\title{
Lojistik ve Tedarik Zinciri Yönetiminde İşbirlikçi Paradigma
}

\author{
Göknur Arzu AKYÜZ *
}

ÖZ

İşbirliği kavramı, Lojistik ve Tedarik Zinciri Yönetimi (TZY)'nde gün geçtikçe önem kazanan en kritik başarı unsurlarından biri haline gelmiştir. Bu çalışmada kapsamlı bir literatür taraması yapılarak, öncelikle işbirliğinin lojistik ve TZY'ndeki rolü ve önemi ele alınmıştır. Daha sonra işbirlikçi anlayışın teknolojik, organizasyonel ve yönetsel boyutlarla ilişkisi detaylı olarak tartışılmıştır. Teknolojik boyutta bilişim teknolojilerinde yaşanan yakın dönem değişimler ve bulut teknolojisi, blockchain gibi çeşitli teknolojiler, günümüz işbirlikçi anlayışını mümkün kılan en önemli unsur olarak irdelenmiştir. Ardından işbirlikçi yaklaşımın organizasyonel ve yönetsel boyuttaki etkileri ortaya konmuştur. İşbirlikçi anlayışın oluşmasında ve ileri seviyelere taşınmasında büyük önem taşıyan firmalar arasındaki güven unsuru kapsamlı olarak tartışılmışır. Bu çalışma, partnerlerarası işbirliğinin zaman içerisinde gelişen ve teknolojik, organizasyonel ve yönetsel tüm unsurları ile birlikte yönetilmesini gerektiren en önemli TZY kavramlarından biri olduğunu ortaya koymuştur. Dolayısı ile taraflar arasında anlık bilgi paylaşımı, birbiri ile entegre ve eşzamanlı iş süreçleri ve birbirine güven unsuru ile bağlı dinamik organizasyonel yapılar günümüz Lojistik ve TZY'nde iş yapış biçimi haline gelmektedir.

Anahtar Kelimeler: İşbirliği, Lojistik, Tedarik Zinciri Yönetimi, Bilişim Teknolojileri, İşbirliğinde Güven

JEL Sinıflandırması: L14, L20, L00

\section{Collaborative Paradigm in Logistics and Supply Chain Management}

\begin{abstract}
Collaboration is a concept becoming increasingly important in Logistics \& Supply Chain Management $(\mathrm{SCM})$ as a critical success factor. Based on a comprehensive literature review, study commences with examining of role and importance of collaboration in Logistics and SCM. Afterwards, relationship of the collaborative understanding with technological, organizational and managerial dimensions are discussed in detail. Recent developments in information technology (IT) and various technologies such as cloud technology and blockchain are analyzed as the most critical enabler of collaboration under technological dimension. Then effects of collaborative paradigm on organizational and managerial dimensions are revealed. Trust concept in a multi-partner context is highlighted in the collaborative paradigm. This study revealed that multi-partner collaboration is one of the most critical SCM concepts evolving in time, and requiring the management of technological, organizational and managerial aspects. Thus, real-time information sharing across partners, integrated syncronized business processes and dynamic organizational structures trusting and dependant on each other became the current paradigm for Logistics \& SCM.
\end{abstract} Collaboration

Keywords: Collaboration, Logistics, Supply Chain Management, Information Technology, Trust in

JEL Classification: L14, L20, L00

Geliş Tarihi / Received: 29.06.2020 Kabul Tarihi / Accepted: 10.11.2020 Doi: 10.17541/optimum. 759696

\footnotetext{
* Doç. Dr., Türk Hava Kurumu Üniversitesi, İşletme Fakültesi, Lojistik Yönetimi Bölümü, arzu.akyuz@gmail.com, ORCID: 0000-0003-2024-5884.
} 


\section{GİRIŞ}

Lojistik ve Tedarik zincirinin gelişimi değerlendirildiğinde, yakın dönemde işletme fonksiyonlarına ve lojistik hareketlerine odaklı ve entegre olmayan bir anlayıştan, gittikçe artan bir şekilde süreç odaklı, entegre, bilgi teknolojisi kullanan ve müşteri odaklı bir anlayışa doğru değişimin gerçekleştiği ve bu değişimin halen sürmekte olduğu görülmektedir (Akyuz ve Gursoy, 2013).

Günümüzde Tedarik Zinciri Yönetiminin damar sistemini oluşturan Lojistik sistemleri, küresel rekabetçi, ekonomik ve teknolojik koşulların sürekli değişimi doğrultusunda gittikçe teknoloji-yoğun ve işbirlikçi bir yaklaşım sergilemektedir (Chen ve Zang, 2011; Pateman, Cahoon ve Chen, 2016; Pomponi vd., 2013). Bilgi Teknolojileri alanındaki çarpıcı değişimler gerek malzeme, gerek bilgi, gerekse para hareketleri ile ilgili tüm veri, bilgi ve birikimin taraflar arasında anlık olarak paylaşımına imkân vermektedir. Bu da ilgili tüm taraflar arasında sadece operasyonel değil, taktik ve stratejik seviyelerde de işbirliğini olanaklı kılmaktadır.

Günümüz lojistik ve tedarik zinciri ilişkilerinde aralarında temel alıcı-satıcı ilişkisi olan, birbirine mesafeli (arms-length) ayrı firmalar anlayışı çok uzaklarda kalmıştır (Ayers, 2010). Gittikçe daha farklı ve artan sayıda süreçte işbirliği yapabilen ve birlikte daha uzun vadeli çalışabilen firma şebekeleri artık kabul gören anlayış olarak kaynaklarda yerini almıştır (Akyuz ve Gursoy, 2013; Li Gu ve Song, 2013).

Dolayısı ile günümüz anlayışında çok aktörlü, birbirine operasyonel, taktik ve stratejik seviyede bağımlı ve gittikçe karmaşıklaşan tedarik şebekelerinin küresel arenada işbirlikçi ve müşteri odaklı bir şekilde değer yaratarak rekabet edebilmesi söz konusudur (Akyuz 2012; Akyuz ve Gürsoy, 2013; Li Gu ve Song, 2013). Bu bağlamda işbirliği kavramı, günümüz lojistik ve tedarik zinciri yönetimi anlayışının en önemli unsurlarından biri haline gelmiştir (Ramanathan ve Gunasekaran, 2014; Simchi-Levi ve Kaminsky, 2007).

$\mathrm{Bu}$ makalede aşağıdaki araştırma sorularına cevap aranmıştır:

- Lojistik ve Tedarik Zinciri Yönetiminde işbirliğinin rolü ve önemi nedir?

- İşbirlikçi yaklaşımda bilişim teknolojilerinin yeri nedir?

- İşbirlikçi anlayışın organizasyonel boyuttaki etkileri nelerdir?

- İşbirlikçi anlayışın yönetsel boyuttaki etkileri nelerdir?

- İşbirlikçi yaklaşımda güven unsurunun rolü ve önemi nedir?

Çalışmada yapılan kapsamlı literatür taramada "Lojistik ve Tedarik Zinciri Yönetimi", "Işbirliğì", "Bilişim Teknolojileri" ve "Güven" anahtar kelimeleri kullanılmıştır. Kaynakçadaki referans seti 2001 yılı ve sonrasındaki kaynakları, ağırlıklı olarak da saygın dergileri, kitap ve kitap bölümlerini kapsamaktadır.

Çalışmanın bölüm yapısı araştırma sorularının doğrultusunda oluşturulmuştur. $\mathrm{Bu}$ çalışmada 2. Bölümde işbirliğinin lojistik ve tedarik zinciri yönetimindeki rolü ve önemi; 3 . Bölümde işbirliğini imkânlı kılan en önemli faktör olarak bilişim teknolojileri; 4. Bölümde işbirlikçi anlayışın organizasyonel boyuttaki etkileri, 5. Bölümde yönetsel boyuttaki etkileri tartış1mıştır. 6. Bölümde güven unsurunun işbirliği için rolü ve önemi, 7. Bölümde ise sonuçlar sunulmuştur. 


\section{LOJISTIK VE TEDARİK ZINCİRI YÖNETIMINDE ISSBİRLIGĞININ ROLÜ VE ÖNEMI}

İşbirliği kavramı, literatürde koordinasyon ve entegrasyon kavramları ile iç içe geçmiş olarak ortaya çıkmaktadır. İşbirliği, koordinasyondan ve entegrasyondan daha üst seviyede bilgi paylaşımı, güven ve bağlılık gerektiren bir kavram olarak tanımlanır (Soosay ve Hyland, 2015). Koordinasyon tedarik zinciri entegrasyonunda kaçınılmaz bir adımdır. İşbirliği kavramı ise teknoloji paylaşımı ve sıkı sıkıya entegre edilmiş planlama ve kontrol sistemleri içermesi nedeniyle entegrasyon kavramının da ötesine geçer (Akyuz, 2012; Soosay ve Hyland, 2015). Dolayısı ile uzun vadeli ve güvene dayalı ilişkilerin en yüksek şekli olarak tanımlanabilir (Bhakoo ve Chan, 2011; Ha vd., 2011; Van Echtelt vd., 2008; Yazici, 2012; Duong ve Chon, 2020).

Partnerler (taraflar) arasındaki artan koordinasyon, entegrasyon ve işbirliği, Lojistik ve Tedarik Zinciri Yönetiminde verimliliği ve performansı arttıran en temel unsurlar olarak ortaya çıkmaktadır (Cao vd., 2010; Chopra ve Meindl, 2016; Li, Gu ve Song, 2013). Artan işbirliğii, aşağıdaki en temel noktalarda iyileştirmeler sağlamaktadır:

•işlem maliyetlerini azaltmakta,

•kamçı etkisini azaltmakta,

•üretim, envanter, taşıma ve sevkiyat maliyetlerini azaltmakta,

•üretim ve teslimat sürelerini kısaltmakta,

•kaynaklara ulaşım ve etkin paylaşımı konusunda iyileştirmeler sağlamakta,

•taraflarda temel yetkinliklerin gelişmesini mümkün kılmakta,

-zincirin genel esnekliği ve değişen koşullara cevap verebilme yetisini arttırmakta,

•kalite iyileştirmeleri sağlamakta,

•risk ve ödüllerin paylaşımını sağlamakta,

-inovasyon yetkinliklerinin artması mümkün olmakta,

-rekabetçi avantajların elde edilmesi ve karlılığın arttırılması mümkün olmaktadır.

$\mathrm{Bu}$ bağlamda işbirliğinin kaynaklar, yetkinlikler, süreçler ve rutin operasyonlar açısından tüm partnerlere yüksek performans ve kazan-kazan iyileştirmeler sağladığ 1 genel kabul görmüştür (Cao vd, 2010; Chao ve Zhang, 2011; Soosay ve Hyland, 2015; Wu ve Chiu, 2018). Tedarik zinciri üzerindeki çeşitli risk unsurlarının işbirlikçi anlayışla çok daha iyi tanımlanıp yönetilebileceği ve tarafların proaktif davranışlar içinde olmasının sağlanabileceği de tedarik zinciri risk yönetimi literatüründe açıkça ortaya konmuştur (Chen, Sohal ve Prajogo, 2013; Fan ve Steveson, 2018; Grötsch, Bloom ve Schleper, 2013; Harland, Brenchley ve Walker, 2003; Lavasatre, Gunasekaran ve Spalanzani, 2012; Duong ve Chon, 2020). Teorik perspektifte bakıldığında, işbirliği ile gelen tüm bu avantajlar ağırlıklı olarak işlem maliyet ekonomisi, kaynak tabanlı bakış açısı, kaynak bağımlılığı ve ilişkisel bakış açısı perspektifleri ile ilişkilendirilmektedir (Cao vd, 2010; Chao ve Zhang, 2011; Ramanathan ve Gunasekaran, 2014). Cao vd. (2010), işbirliği kavramı ile ilgili aşağıdaki temel boyutları tanımlamaktadır: a) bilgi paylaşımı; b) hedeflerde uyum; c) karar senkronizasyonu; d) teşviklerin uyumlandırılması, e) kaynak paylaşımı, f) işbirlikçi iletişim ve g) ortak bilgi yaratımı. İşbirliği kavramı geliştikçe iki ya da daha fazla firmanın arasında: a) çeşitli süreçlerde birlikte planlama, yürütme, kontrol ve karar alma mekanizmaları geliştirmesi; b) kaynak, süreç, ödül ve risklerin paylaşılması; c) karşılıklı anlayış ve güven tesis edilmesi; c) kritik bilgi paylaşımının sağlaması ve d) ortak hedeflerle uzun vadeli iş ortaklıklarının oluşması söz konusu olmaktadır (Soosay ve Hyland, 2015). 
Bu konuda CPFR (Collaborative Planning, Forecasting and Replenishment- İşbirlikçi Planlama, Tahminleme ve Yenileme) modeli halen strateji ve planlama, talep ve kaynak yönetimi, yürütme ve analiz boyutlarında ilgili tüm partnerlerin işbirliğine dayalı en kapsamlı modellerdendir (VICS, 2002).

Görüldüğü üzere işbirliği kavramı sadece operasyonel seviyedeki faaliyetlerin ve temel malzeme yönetimi aktivitelerinin birlikte gerçekleştirilmesi ve koordinasyonundan çok daha geniş bir kavramdır. İşbirliğinde gerek operasyonel, gerek taktik, gerekse stratejik seviyede birlikte iş yapabilirlik, koordinasyon ve uyum gerekmektedir. Bu da partnerler arasında iletişim, veri paylaşımı, hedefler arası uyum, karar mekanizmalarında uyum, teşviklerin uyumlandırılması, kaynak paylaşımı, risk ve ödül paylaşımı ve ortak bilgi birikiminin oluşmasını gerektirir (Chao ve Zhang, 2011). Günümüzde işbirliği tedarik zinciri esnekliği yaratmak için en temel prensiplerden biri olarak görülmekte (Smith, Watson, Baker ve Pokorsky II (2007), ve tedarik zinciri sürdürülebilirliği açısından kritik bir rol oynamaktadır (Cloutier, Oktaei ve Lehoux 2020). Bu noktada işbirliği kavramı, tedarik şebekesindeki tüm firmalar açısından gittikçe stratejik öneme sahip bir unsur olarak ortaya çıkmakta ve küresel rekabet açısından bir stratejik yönetim aracı haline gelmektedir (Akyuz, 2012).

Firmalar arasında gerçekleşen tüm süreçler için işbirliği kavramından bahsedilebilir (tüm lojistik, üretim ve envanter planlama süreçleri, tedarikçi yönetimi süreçleri, müşteri ilişkileri yönetimi süreçleri, kalite yönetimi süreçleri, insan kaynakları süreçleri, risk ve performans yönetimi, hatta uzun vadeli ortak finansal yönetim süreçleri gibi). İşbirliği kapsamında öncelikli olarak paylaşılması ve yönetilmesi gereken en temel bilgiler: satış tahmini, stok durumu, üretim planları, üretim durumu ve satın alma durumudur. $\mathrm{Bu}$ anlamda temel malzeme yönetimi aktivitelerinin birlikte, entegre ve senkronize bir biçimde yönetilmesi işbirlikçi anlayışın temelini oluşturmaktadır. Partnerlerin bu temel süreçler üzerinde anlık veri paylaşımı yapabilmeleri, birlikte plan geliştirebilmeleri ve ortak kontrol ve karar mekanizmaları oluşturabilmeleri işbirlikçi yaklaşımda esastır. Bu noktada temel taşıma, depolama, sevkiyat ve gümrük hareketlerinin tüm partnerler arasında anlık izlenebilirliği ve koordinasyonu, yani lojistik yönetimindeki işbirliği, diğer tüm tedarik zinciri yönetimi süreçlerindeki (kalite yönetimi, risk ve performans yönetimi, finans yönetimi gibi) işbirliğinin önkoşulunu oluşturmaktadır. En temel fonksiyonları işbirlikçi bir şekilde yönetemeyen bir yapının stratejik, uzun vadeli ve daha kritik seviyede veri paylaşımı gerektiren süreçlerde işbirliği yapması elbette beklenemez.

$\mathrm{Bu}$ anlayışta, Tedarik Zinciri yönetiminde işbirlikçi yaklaşımın zaman içinde belli bir olgunlaşma yaşayarak farklı olgunluk seviyelerinden geçtiği kaynaklarda sıkça yer bulmaktadır (Akyuz, Gursoy ve Celebi, 2014; CMMI, 2012; Dung, Arun ve Nirajan, 2016). Bu olgunlaşma sürecinde partnerlerin birlikte yönetebildiği süreçlerin sayısı ve kapsamı zamanla adım adım artmaktadır. Öncelikle lojistik süreçlerde işbirliği ve eş zamanlılık (synchronization) sağlandıktan sonra, daha uzun vadeli süreç, kaynak ve iş paylaşımları oluşmaktadır. Partnerler arasında temel yetkinlikler (core competency), roller ve iş paylaşımları gelişmekte ve uzun vadeli dış kaynak kullanım ortaklıkları (outsourcing) hayata geçirilmektedir. Böylece gittikçe daha stratejik seviyedeki süreçlerde işbirliği mümkün olmaktadır.

$\mathrm{Bu}$ olgunlaşma sürecinde taraflar gittikçe birbirine bağımlı, birlikte hareket edebilen, aralarında çıkar çatışması ve firsatçı davranışların olmadığı yapılara dönüşmektedirler. $\mathrm{Bu}$ noktada işbirlikçi yapıların içinde yer alan firmaların tek bir firmanın çıkarına değil, tüm şebekenin uzun vadeli çıkarına uygun olarak stratejik kararları alabilmesi ve uygulamaya koyabilmesi en büyük yönetsel anlayış değişimi olarak ortaya çıkmaktadır.

Özetle, işbirlikçi tedarik zinciri anlayışında firmalar artık uzun vadeli ortak çıkarların ve bağımlılıkların söz konusu olduğu, ortak bir ekosistem içinde birlikte yaşamayı öğrenen organizmalar haline gelmektedir. 


\section{3. İŞBİRLIKKÇI YAKLAŞIMDA BILLIŞIMM TEKNOLOJILERI}

Yukarıdaki temel özelliklere sahip olan işbirliği kavramını mümkün kılan en önemli faktörün BT olduğu literatürde çok sayıda çalışma ile ortaya konmuştur (Akyüz, 2012; Fawcett vd., 2011; Gunasekaran ve Ngai, 2004; Smith vd., 2007). Partnerler arasında anlık veri paylaşımını sağlayan web tabanlı entegre sistemler günümüzde her planlama seviyesinde (operasyonel, taktik ve stratejik seviyelerde) veri ve bilgi paylaşımının alt yapısını oluşturmaktadır.

Firma içinde sağlıklı yürüyen bir Kurumsal Kaynak Planlama (Enterprise Resources Planning-ERP) sistemi altyapısı, firmalardaki süreç entegrasyonunun temeli olarak kabul edilmektedir (Adaileh ve Abu-alganam, 2010; Bendoly ve Jacobs, 2005; Tarn, Yen ve Beaumont, 2002). Bu sistemler işletmedeki satın alma, envanter yönetimi, satış, muhasebe, finans, kalite yönetimi gibi tüm süreçlerle ilgili gerek operasyonel, gerek taktik, gerek stratejik seviyedeki tüm veri ve bilgilerin tutarlı bir şekilde oluşturulmasına ve raporlanmasına olanak sağlamaktadır.

Bu tür yazılım paketleri yine aynı platform üzerinde her kademe yöneticiye anlık karar destek sunabilecek, akıllı raporların elde edilmesine ve verinin "iş zekâsı"na (business intelligence) dönüşmesine imkân verecek ilave modüllerle birlikte sunulmaktadırlar. Veri madenciliği (Data Mining) araçları bu tür ilave modüllerin en önemlileri haline gelmiştir. OLAP (On-line Analytical Processing) kübü mantığı ile çok farklı kırılımlarda ve çok boyutlu özet yönetici raporları almak mümkündür (Brogden vd., 2017; Laudon ve Laudon, 2016). Dolayis1 ile gerek lojistik, gerekse finansal süreçlerin entegrasyonunda ERP sistemleri en önemli unsur olarak ortaya çıkmaktadır.

Firma içi entegrasyonun sağlanmasından sonra, işbirliğinin firmalar arası seviyeye çıkarılması için partner firmaların kullanmakta olduğu farklı süreç ve alt yapıların birbiri ile iletişim halinde olmaları gerekmektedir. Dolayısı ile farklı kurumsal kaynak planlama (ERP) sistemlerinin birbiri ile konuşabilmesi ve entegrasyonu, ortak iş süreçlerinin oluşturulması ve bu süreçlerin işbirlikçi olarak planlanması, gerçekleştirilmesi ve kontrolü konusunda en önemli ihtiyaç olarak ortaya çıkmaktadır.

Günümüzde web servisler ve servis tabanlı mimari (SOA-Service Oriented Architecture) teknolojileri ile tamamen farklı lokasyonlarda ve farklı teknolojik altyapıdaki platformların birbiri ile konuşmaları artık mümkündür (Laudon and Laudon, 2016). Gerek teknik alt yapı gerek boyut gerekse lokasyon açısından tamamen farklı kurumsal sistemlerin birbiri ile anlık iletişimi mümkün hale gelmiştir. Bu da farklı ERP sistemleri arasında veri, bilgi ve raporların paylaşımına ve ortak işbirlikçi süreçlerin kurulmasına imkân sağlamaktadır. Dolayısı ile günümüz kurumsal sistemleri artık şirket içerisinde geliştirilmiş izole yazılım parçacıkları olmaktan çıkarak işletmenin tüm fonksiyonlarını web tabanlı olarak yönetebilen ve farklı firma sistemleri ile konuşabilen "Kurumsal Entegrasyon Platformları-Enterprise Application Integration Platforms" haline dönüşmüştür. $\mathrm{Bu}$ tür yazılım paketleri günümüzde süreç yapılandırma, raporlama, uyarı, yönetici paneli ve iş zekâsı gibi çok kapsamlı bütünleşik fonksiyonlara ve yeteneklere sahiptir (Laudon and Laudon, 2016).

Bulut teknolojisi ile birlikte, firmalar tüm bu platformların en yüksek sürümlerine, fonksiyonlarına ve ilgili tüm BT hizmetlerine: a) yüksek ilk yatırım maliyetlerine gerek kalmadan, b) servis sağlayıcı firma aracılığıyla ve c) kullanımla orantılı ödeme mantığıyla kolayca ulaşabilir hale gelmiştir (Akyuz ve Rehan, 2015; Buyya, Broberg ve Goscinski, 2011; Shacklett, 2012). BT de dış kaynak kullanımını temsil eden bu yapı artık bütün kurumsal entegrasyon platformlarının kullandığı bir teknoloji haline gelmiştir. Böylelikle, hâlihazırda farklı seviyede ve çeşitlilikteki BT altyapısı ve araçlarına sahip ve farklı boyuttaki firmalar, tedarik zinciri işbirliği için gerekli olan iletişim altyapısına ve araçlarına ulaşabilir ve birbiri ile 
konuşabilir hale gelmektedir. $\mathrm{Bu}$ durum, özellikle KOBİ ler için çok önemli firsatlar sunmaktadır. Bulut teknolojisi ile KOBİ ler ilk yatırım kısıtından dolayı ulaşamayacakları ve büyük şirketlerin kullandığı teknolojik alt yapılara ulaşabilme imkânını bulmaktadır. Dolayısı ile alt yapıları farklı olsa da KOBİ'ler büyük firmalarla konuşabilir, bilgi paylaşabilir ve işbirliği yapabilir hale gelmektedir. Bu durum da farklı boyutlarda firmalar arasında işbirlikçi bir ekosistem kurma konusunda en büyük yardımcı olarak ortaya çıkmaktadır.

Bar kod, RF/ID, GIS (Geographical Information Systems), POS (Point of Sales Systems), mobil teknoloji gibi farklı teknolojilerle ERP sistemlerine anlık veri sağlamak artık günümüz tedarik zinciri yönetiminin her noktasında iş yapış biçiminin bir parçası olmuştur. Envanter, satış, satın alma ve gümrük süreçleri ile ilgili durum bilgileri firmalar arasında anlık ve şeffaf olarak paylaşılabilmektedir. Böylelikle bu teknolojiler lojistik yönetimindeki "izlenebilirlik" kavramının olmazsa olmazları haline gelmiştir. Örneğin günümüzdeki araç takip sistemlerinde bu tür teknolojilerin birlikte kullanımı ile sahadaki tüm dağıtım araç filosunun anlık takibi mümkün olmaktadır. Yine sahadaki tüm satış ekibinden ERP sistemine anlık veri girişi artık işin doğası haline gelmiştir.

Blockchain teknolojisi anlık işlem güvenliği, veri paylaşımı ve izlenebilirlik konusunda lojistik ve tedarik zincirinde gelecek vadeden en önemli teknolojilerden biri olarak karşımıza çıkmaktadır (DHL, 2018; Heütgel ve Kückelhaus, 2018). Bu teknolojinin en temel özelliği, değiştirilemez ve şeffaf olarak tüm firmaların ulaşabildiği bir işlem kaydı altyapısı sağlamak ve böylece tüm firmaların simetrik ve güvenilir bilgiye ulaşmasına imkân vermektir (Akyuz ve Gursoy, 2018; Kamble, Gunasekaran ve Arha, 2019). Herhangi bir işlem veya bilginin üzerinde oynanmadığı garanti edilmekte ve kaynağının kesin olarak doğrulanması ile firmalar arasında şeffaflık ve güvenilirliğin sağlanması söz konusu olmaktadır. Bu nedenle teknolojinin lojistikte özellikle ürünün kaynağının takibi, ürün orijinalliğinin doğrulanması, sahte ürün takibi (özellikle gıda ve ilaç üretimi sektörlerinde), değerli ürün takibi (mücevher, pahalı moda ürünleri gibi), uçtan uca seri numarası takibi gibi konularda çok önemli iyileştirmeler sağlayacağı beklenmektedir (DHL 2018). Blockchain uygulamalarının uluslararası ticaretle ilgili tüm dökümantasyonun ve idari süreçlerin sadeleştirilip hızlandırılmasında ve her türlü gümrük işleminin hızlanıp şeffaflaşmasında çok büyük potansiyel taşıdığı değerlendirilmektedir. Dijital dokümanların ve gerçek zamanlı sevkiyat verisinin blockchain üzerinde tutularak akı1lı kontratlarla birlikte kullanımı, tüm lojistik hareketlerindeki verimliliğin ve izlenebilirliğin arttırılması için önemli bir potansiyel taşımaktadır. Süreç boyunca kullanılan dokümanlar arasındaki uyuşmazlıkların giderilmesi ve belli koşulların sağlanıp sağlanamadığının işlem anında otomatik kontrolü, blockchain in getireceği verimlilik unsurlarının başında sayılabilir.

Endüstri 4.0 felsefesi, IoT (Nesnelerin İnterneti) paradigmas1 ve akıllı sistem teknolojileri ile zincirin her noktasındaki farklı nesnelerin birbirleri ile konuşabilmeleri sağlanmaktadır (Bonavolonta, 2017; Hofmann ve Rüsh, 2017). Bu anlayışta akıllı depo sistemleri, robot kollar, CNC tezgâhlar, kamyonlar, drone'lar, vinçler gibi üretim ve lojistik hareketlerinin parçası olan tüm nesneler sensörler aracıllğ gelmiştir. Böylelikle gerçek zamanlı izlenebilirlik ve kurumsal sistemlere anlık veri akış1 olanaklı hale gelmiştir. Bu nesnelerden alınan veriler yöneticilere yönelik anlık raporlamalara hızla dönüştürülebilmekte ve bu tür raporlamalarda gittikçe daha akıllı hale gelen algoritmalar ve yapay zekâ uygulamaları kullanılmaktadır. Dolayısı ile firmalar arasında sadece operasyonel seviyede değil, daha üst düzey raporlamalarda anlık izlenebilir ve paylaşılabilirlik sağlanmaktadır. Akıllı depo sistemleri, akıllı yükleme uygulamaları, sürücüsüz taşıma imkânları, otonom araçlar, akıllı rotalama algoritmaları günümüz lojistik ve tedarik zincirini yönetiminin parçası haline gelmekte ve lojistik sistemleri gün geçtikçe gittikçe daha akıllı sistemlere dönüşmektedir. $\mathrm{Bu}$ anlamda lojistik yönetimi, Endüstri 4.0 uygulamalarına çok uygun olan alanlardan biri olarak ortaya çıkmaktadır (Hofmann ve Rüsh, 2017). 
$\mathrm{Bu}$ kısımda bahsi geçen tüm bu teknolojilerle, artık farklı firmalardaki işlem verileri, veri tabanları, raporlar ve yönetici panelleri istenildiği anda ve anlık olarak paylaşılabilir hale gelmiştir. Bu da tedarik zinciri işbirliği kavramının teknolojik altyapısını oluşturmaktadır.

\section{4. İŞBİRLİKÇİ YAKLAŞIMIN ORGANIZASYONEL BOYUTTAKİ ETKILIERİ}

Yukarıda bahsi geçen teknolojik değişimlerle birlikte, gittikçe daha etkin bir şekilde veri paylaşabilen, birbirine daha bağımlı ve daha esnek organizasyon yapıları söz konusu olmaya başlamışıır. Firmalar arasında artan anlık veri paylaşımı ve iletişim, hiyerarşik ve bürokratik bir organizasyonel yapılanmadan hızlı hareket edebilen, anlık kararlar alabilen esnek organizasyon yapılarına doğru bir değişime neden olmaktadır (Akyuz ve Gursoy, 2015; Camarinha-Matos ve Afsarmanesh, 2008). Hiyerarşik ve çok katmanlı yapılar artık sağlıklı veri iletişimine, verimliliğe ve rekabetçi avantaja katkı sağlayamamaktadırlar. Dolayısı ile organizasyon yapıları gittikçe sadeleşip esnekleşmeye ve dinamikleşmeye doğru gitmektedir. "Yalınlık" ve "çeviklik" kavramları şirketlerin rekabetçi avantajı için en temel özellikler olarak ortaya çıkmaktadır.

Bu felsefede şirketler arası dinamik, yetkilendirilmiş ve gerekli "yönetici karar desteği”" imkanları ile donatılmış ekiplerin koordinasyonu ve işbirliği, başarının anahtarı ve yeni iş yapış biçimi haline gelmektedir.

Organizasyonun sınırları dışına taşan "birlikte iş yapabilirlik", açık iletişim ve entegrasyonu anlatmak üzere, "organizasyonel sinırların bulanıklaşması (blurred organizational boundaries) ifadesi literatürde siklıkla yer bulmaktadır (Baraldi vd., 2014; Jones, 2013). Firma içinde bölümler arasındaki fonksiyonel duvarların ortadan kalkmasına benzer bir şekilde, firmalar arasındaki coğrafi, idari ve teknolojik keskin sınırlar da gittikçe bulanıklaşmaktadır. Dolayısı ile günümüzde firmalar için "açık bir ekosistem" içinde iyi takım oyuncusu olmak söz konusudur.

Bütün bu organizasyonel değişimlerle birlikte, yeni anlayıştaki firmaların temel özellikleri aşağıdaki şekilde özetlenebilir: süreç odaklı, dinamik adaptasyon yeteneğine sahip, yalın ve çevik, ortak hedeflere kilitlenmiş, karşılıklı bağımlı ve düz/yatay hiyerarşiye sahip.

Organizasyon yapıları ile ilgili olarak yaşanan bu değişimlerle birlikte, çok sayıda yeni terminoloji de literatürde yerini almaya başlamıştır. Genişletilmiş kurumlar, sanal organizasyonlar ve sanal şebekeler bu yeni terim ve kavramların başında gelmektedir.

Özetle, günümüz rekabetçi ortamında organizasyonlar birbirine gittikçe daha fazla entegre, daha az hiyerarşik, daha yalın ve çevik yapılara dönüşmektedirler.

\section{5. İŞBİRLIKÇCI YAKLAŞIMIN YÖNETSEL BOYUTTAKİ ETKILERİ}

Yukarıda bahsi geçen teknolojik ve organizasyonel değişimler, yönetsel anlayışta da önemli değişimlere sebep olmaktadır. Yönetsel anlamda sadece tek bir firmanın değil, birden fazla firmanın ortak stratejik hedefler ve çıkarlar doğrultusunda yönetilmesi gerekmektedir. Dolayısı ile firma seviyesindeki yönetim kontrol anlayışından şebeke seviyesinde yönetim kontrol anlayışına doğru bir değişim gerçekleşmektedir (Akyuz, 2012). Bu anlayışta öne çıkan en önemli unsurlar şunlardır:

-partnerler arası stratejik hedef ve amaçların tutarlılı̆̆ının sağlanması,

• ortak yönetilen süreçler ve işbirlikçi karar verme mekanizmalarının geliştirilmesi,

-firmalar arası proaktif, çok-kademeli yönetsel raporlama ve erken uyarı sistemleri geliştirilmesi. 
İşbirlikçi anlayışta, tek bir firmanın performansının maksimize edilmesi veya riskinin minimize edilmesi uzun vadeli işbirliği açısından tüm şebekenin iyiliği anlamına gelmemektedir. Yine bazı performans ve risk kriterlerinin en iyilenmesi farklı birtakım diğer kriterlerde kötüleşmeye sebep olabilmektedir. Bu nedenle tüm performans ve risk unsurlarının bütünsel, sistemik bir anlayışla ve firma bazında değil tüm şebeke bazında yönetilmesi temel yaklaşımdır (Akyuz, 2012). Bütün iş süreçleri için ve her yönetsel seviyede (operasyonel, taktik ve stratejik), çok kültürlü bir ortamda ve şebeke seviyesinde izlenebilirlik ve hesap verilebilirlik söz konusudur. $\mathrm{Bu}$ noktada özellikle temel lojistik süreçlerdeki performans iyileştirmeleri ve risklerin minimize edilmesi, tedarik zincirinde kan dolaşımının sürekliliği anlamına gelmekte ve hayati önem taşımaktadır. Bu süreçlerde elde edilecek iyileştirmeler ve kurulacak proaktif firmalar arası mekanizmalar, zincirdeki faaliyetlerin kesintiye uğramaması, sürdürülebilirliği ve uzun vadede rekabetçiliği açısından büyük önem taşımaktadır.

Dolayısı ile artık klasik firma odaklı verimlilik, performans ve risk değerlendirme sistemleri yerine tüm şebekenin nabzını tutabilecek sistem ve ölçümlere ihtiyaç vardır. Şebeke seviyesinde ölçme ve kontrol sistemleri, ortak metrik ve takip mekanizmalarının geliştirilmesi gerekmektedir (Akyuz, 2012; Akyuz ve Gursoy, 2013). Bu bağlamda şebeke seviyesinde işbirlikçi performans ve risk yönetim sistemlerinin geliştirilmesi ve hayata geçirilmesi söz konudur. Literatürde de "kurumsal performans yönetimi" ve "kurumsal risk yönetimi" alanlarının giderek "tedarik zinciri performans yönetimi" ve "tedarik zinciri risk yönetimi”ne evrilmekte olduğu açıkça görülmektedir (Arena, Arnaboldi ve Azzone, 2010; Ghadge, Dani ve Kalawsky, 2013). Görüldüğü üzere bu tür sistemlerin hayata geçirilmesi ancak uzlaşmacı ve uzun vadeli bakış açısına sahip bir üst yönetim anlayışı ile mümkün olabilir.

$\mathrm{Bu}$ anlayışta başarılı bir liderden beklentiler ve ideal lider özellikleri de elbette değiştirmektedir. Çatışma yönetimi ve şirketler arası müzakere yetenekleri olan, uzlaşma kültürüne ve açık iletişime inanan, koçluk/rehberlik tarzı yönetim anlayışını benimseyebilecek liderlerin varlığı işbirlikçi bir kültürün yeşermesine imkân verecektir.

\section{6. İŞBİRLİKÇI YAKLAŞIMDA GÜVEN UNSURU}

Yukarıdaki bölümlerde açıkça ortaya konduğu üzere, "Lojistik ve Tedarik Zinciri Yönetimi işbirliği" kavramı sadece teknolojik boyutun değil, organizasyonel ve yönetsel boyutların da yönetilmesini gerektirmektedir. Üçüncü bölümde tartış1ldığı üzere, işbirliği amaçlı kullanılabilecek teknolojik imkânlar üst düzey seviyelere ulaşmış durumdadır ve birçok araç ve teknoloji bir arada kullanılabilmektedir. Dolayısı ile partnerler arası işbirliğinin hayata geçirilmesinin önündeki en temel engel artık teknolojik unsur değildir. Tam tersine, organizasyonel ve yönetsel boyuttaki engeller işbirliği konusunda aşılması en zor olan unsurlar olarak görülmektedir.

$\mathrm{Bu}$ noktada firmalar arasındaki güven kavramı işbirliği kapsamını belirleyen en temel unsur ve uzun vadeli stratejik ilişkilerin ön koşulu olarak görülmektedir (Başkol, 2014; Skandrani, Triki ve Baratli, 2011).

Firmalar arasında yüksek oranda bağımsız/ bireysel davranma eğilimi söz konusudur (Başkol, 2014). Tıpkı insan ilişkilerinde olduğu gibi, kendi şirket çıkarını diğer firmanın çıkarından önde tutma, ortaya çıkan çeşitli durumlarda firsatçlık yapma ve diğer firmanın iyi niyetini ve verilerini kötüye kullanma sıklıkla görülür. Bu noktada gelişen güven kavramı partnerler arasındaki fırsatçı davranışı minimuma indirir, bilgi asimetrisini azaltır ve güçlü firmanın nispeten dezavantajlı firmayı paydaş olarak görmesini sağlar. 
Literatüre bakıldığında, tedarik zinciri yönetiminde "firmalar arasındaki güven" kavramı ile "işbirliği" kavramı arasında pozitif bir ilişki olduğu kabul görmektedir (Başkol, 2014; Das ve Teng, 2001; Dirks ve Ferrin, 2001; Sundaramurthy ve Lewis, 2003). Konunun tedarik zinciri performansına direk olumlu etkileri olan en önemli unsurlarından biri olduğu (Başkol, 2014; Robson, Katsiekas ve Bello, 2008;), risk yönetimi ile yakın ilişki halinde olduğu (Harlan vd., 2003) ve artan güvenin tedarik zinciri yönetimindeki çeşitli risk unsurlarının azaltılmasında önemli rol oynadığı (Das ve Teng, 2001) literatürde sıkça bahsedilmektedir. Dolayısı ile firmalar arasındaki güven unsuru performans ve risk yönetimini direk etkileyen en önemli faktörlerden biri olarak ortaya çıkmaktadır.

Birinci bölümde detaylı olarak ortaya konduğu üzere günümüz işbirliği kapsamı operasyonel seviye işbirliğinden (anlık envanter verisi ve işlem verileri paylaşımı gibi) ibaret değildir. Partnerler gittikçe artan bir şekilde çok daha stratejik konular üzerinde (ortak performans ve risk yönetimi, stratejik pazar ve yeni ürün geliştirme kararları gibi) işbirliği yapmaya başlamaktadırlar. Bu noktada firmalar arasında hassas birtakım veri ve bilgilerin (maliyet bilgileri, yeni tasarım bilgileri, finansal veriler gibi) paylaşımında doğal olarak çeşitli çekinceler oluşmaktadır. Bu tür bir paylaşım ancak karşılıklı güvene dayalı bir ortamda söz konusu olabilir. Diğer firmanın paylaşılacak bilgiyi kötüye ya da sadece kendi çıkarına kullanmayacağını bilmek ve uzun vadede gerçekten tüm partnerlerin çıkarına kararlar almak için kullanacağından emin olmak, yani karşıllklı güvenin tesis edilmesi gerekir.

$\mathrm{Bu}$ bağlamda güven unsuru literatürde karşılıklı uzun vadeli ilişkileri destekleyen, çok boyutlu, karmaşık ve modellenmesi zor bir kavram olarak ortaya çıkmaktadır (Bunduchy, 2008; Smith ve Smith, 2003). Güven simetrik veya geçişli değildir. Yani, A partnerinin B ye güvenmesi, B'nin A'ya güvenmesi anlamına gelmez. Yine A'nın B'ye, B'nin de C'ye güvenmesi, A'nın C'ye güvenmesi gerektiği anlamına da gelmez. Dolayısı ile tedarik zinciri kapsamında çoklu ilişkilerdeki güven unsuru değerlendirilirken tüm asimetrik durumların göz önüne alınması gerekir.

Güven unsurunu etkileyen çeşitli faktörlere bakıldığında, kaynaklarda çok farklı sınıflamaların yanında birbiri ile örtüşen kavramlar ve farklı kavramların birbiri yerine kullanımı sıklıkla görülmektedir (Akyuz ve Gursoy, 2014). Karşı firmanın uzmanlığı, tutarlılığ işlemlerdeki deneyimi, iyi niyeti, açıklığı, ilişkiye olan sadakati, dürüstlüğü, ilişkinin süresi gibi pek çok unsurun karşılıklı güveni etkilediği ortaya konmuştur (Akyuz ve Gursoy, 2014; Başkol, 2014; Cengiz ve Aksoy, 2007).

Dolayısı ile firmalar arasında güvenin oluşması için ortak amaç ve hedef birliği, ortak çıkar, kısa vadeden ziyade uzun vadeli ilişkilere önem verilmesi ve bireysel çıkarlar yerine tedarik zinciri seviyesindeki performansin maksimizasyonu gerekmektedir. Bu da doğal olarak açıklık ve iyi niyete dayalıdır. Firmaların zaman içinde gelişen karşılıklı güvenle birlikte "ben" değil "biz" demeyi öğrenmesi ve kendi bireysel çıkarları yerine tüm tedarik zincirinin çıkarı doğrultusunda hareket etmeyi benimseyebilmesi söz konusudur. Ancak bu durumda stratejik planların, riskleri ve ödülleri paylaşabilmesi ve uzun vadeli ve stratejik kapsamlı işbirlikleri sağlanabilecektir.

Anlaşılacağı üzere bu tür bir güven seviyesinin tesis edilebilmesi, sadece operasyonel ve taktik seviyedeki kişilerin ve ekiplerin iyi iletişimi ve güveni ile sağlanamaz. En üst seviyedeki yöneticilerin iyi niyet beyanı, ortak hedeflerde uzlaşması ve açıklığına ihtiyaç vardır. Bu durum üst düzey ekiplerde önemli anlayış ve yaklaşım değişiklikleri gerektirmektedir. Karşı firmanın öncelik ve çıkarlarına değer verme, firmaların tedarik zinciri yapısı içerisinde birbirlerine bağımlı ve muhtaç olduğunun farkındalığı, her türlü firsatçı davranışın bir kenara konulup uzun vadeli çıkarların öne alınması ve uzlaşmacı yönetim anlayışının benimsenmesi gerekmektedir. $\mathrm{Bu}$ anlayış değişimi benimsenmediği takdirde işbirliği kapsamının operasyonel seviyenin üzerine çıkması beklenemeyecektir. 


\section{SONUÇ}

$\mathrm{Bu}$ çalışmada öncelikle lojistik ve tedarik zinciri yönetiminde işbirlikçi yaklaşımın rolü ve önemi tartışılmıştır. İşbirliği kavramının günümüz küresel rekabet koşullarında başarıyı yakalamak için lojistik ve tedarik zinciri yönetiminin olmazsa olmazı haline geldiği açıkça ortaya konmuştur.

Bilişim teknolojileri, sunduğu sınırsız imkânlarla işbirliğini mümkün kılan en kritik unsur olarak ortaya çıkmıştır. Kurumsal kaynak planlama sistemlerini merkez alan ve bu sistemlerle entegre olarak çalışan farklı teknolojiler günümüz işbirliği altyapısını oluşturmaktadır. Bulut teknolojisi, IoT, akıllı sistemler, blockchain gibi birçok yakın dönem teknoloji işbirlikçi ekosistemlerin parçası haline gelmeye başlamıştır. Bu teknolojilerle gerek tedarikçi, gerek üretim, gerekse satış dağıtım kanallarından gerçek zamanlı veri, bilgi ve birikim paylaşımı artık tamamen farklı boyutlara ulaşmıştır. Partnerler arasında gerek malzeme, gerek bilgi, gerekse para akışının izlenebilirliği ve şeffaflığı artık gerçek zamanlı olarak sağlanabilmekte, her türlü işlem ve raporlama açısından taraflar arasında hesap verilebilirlik mümkün olmaktadır. Web tabanlı teknolojik altyapı sayesinde coğrafi lokasyonları, mevcut teknik alt yapıları ve büyüklükleri ne olursa olsun firmalar ekosisteme dinamik olarak dâhil olabilmekte, yani lojistik ve tedarik zinciri şebekeleri dinamik olarak yapılandırılabilmekte ve ölçeklendirilebilmektedir. Bu durum, esnek organizasyonel yapılara ve dinamik işbirliklerine yol açmaktadır. Temel yetkinliklerin tedarik zincirinde dinamik olarak kullanımı, yeni işbirlikleri ve yeni yetkinliklerin kazanılması mümkün olmaktadır. Farklı süreçlerden sorumlu dış kaynak sağlayıcıları (örneğin lojistik hizmet sağlayıcıları, BT hizmet sağlayıcıları) ile işbirlikleri ve birlikte yürütülen izlenebilir iş süreçleri tedarik zinciri başarısının en önemli unsurlarından biri haline gelmiştir. $\mathrm{Bu}$ noktada bulut teknolojisinin yaygın kullanımı ile birlikte, bilişim teknolojilerinde uzmanlaşmış firmalar BT hizmet sağlayıcı olarak tedarik zincirinin kritik oyuncuları haline gelmektedir.

Teknolojik tarafta oluşan yıkıcı değişimler açıkça tedarik zinciri işbirliğini mümkün kılan en önemli unsur olarak ortaya çıkmıştır. Ancak tüm bu teknolojik değişimin yönetilmesi işbirliği için yeterli olmamaktadır. Konunun sadece teknolojik boyutunun olmadığı, ilgili tüm teknolojik unsurların etkin bir şekilde yönetilmesinin yanında organizasyonel ve yönetsel boyutta anlayış değişiminin yaşanması ve firmalar arasında güven tesis edilmesi gerektiği çalışmada detaylı olarak tartışılmıştır. Dolayısı ile işbirlikçi yaklaşımla birlikte teknolojik tarafta bir paradigma değişimi yaşanırken, organizasyonel ve yönetsel değişimler de söz konusudur. Bu noktada yeni paradigma açıklık ve uzlaşmaya dayalı, değişime açık ve karşılıklı güvenin olduğu bir firma kültürü, iş yapış biçimi ve liderlik anlayışına ihtiyaç duymaktadır.

Bundan sonraki araştırmalarda, bahsi geçen bilişim teknolojiklerindeki çeşitli gelişmelerin tedarik zinciri işbirliği konusunda farklı sektörlerdeki uygulamaları, bu sektörlere getirdiği veya getirebileceği potansiyel verimlilikleri inceleyen, özellikle vaka bazlı, sektör bazlı ve sektörler arası karşılaştırmalı çalışmaların literatüre katkı sağlayacağı düşünülmektedir. Yine bu teknolojilerin organizasyonel ve yönetsel boyutta yarattığ 1 değişimler ve organizasyon teorisi ile ilişkilerinin vaka bazlı çalışmalarla ortaya konması katkı sağlayan çalışmalar olacaktır.

\section{Araştırma ve Yayın Etiği Beyanı}

Bu çalışma bilimsel araştırma ve yayın etiği kurallarına uygun olarak hazırlanmıştır.

\section{Yazarların Makaleye Katkı Oranları}

Yazarın makaleye katkısı \%100'dür.

\section{Çıkar Beyanı}

Yazarlar açısından ya da üçüncü taraflar açısından çalışmadan kaynaklı çıkar çatışması bulunmamaktadır. 


\section{KAYNAKÇA}

Adaileh, M.J., \& Abu-alganam, K.M. (2010). The Role of ERP in Supply Chain Integration. International Journal of Computer Science and Network Security, 10 (5), 274-279.

Akyuz, G.A. (2012). E-Collaboration based Management Control Model for Supply Chains. PhD Thesis, Attlım University.

Akyuz, G.A., \& Gursoy, G. (2013). Paradigm Shift in Supply Chain Management. Invited Speech and published article, for ASEM, American Society for Engineering Management 2013, International Annual Conference, 2-5 Oct. 2013, Minneapolis-Minnesota.

Akyuz, G.A., \& Gursoy, G. (2014). Role of Management Control and Trust formation in Supply Network Collaboration. International Journal of Collaborative Enterprise, 4(3), 137-159.

Akyuz, G.A., Gursoy, G., \& Celebi, N. (2014). Supply Chain Collaboration Maturity: A Conceptual Model. IGI Group, Encyclopedia of Business Analytics and Optimization (Ed. by John Wang), 5, 2333-2349, IGI Group.

Akyuz, G.A., \& Gursoy, G. (2015). Change in organizational paradigms in complex supply Networks. ICOVACS 2015, International Congress on Value Chain Sustainability, 248-254. 12-13 March, 2015, Marmara University, Istanbul-Turkey.

Akyuz, G.A., \& Rehan, M. (2015). Supply Chain in the Cloud: Opportunities, Barriers and a Generic Treatment. Advanced Research on Cloud Computing Design and Applications, (Ed. By Shadi Aljawarneh), IGI Group, 24-36.

Akyuz, G.A., \& Gursoy, G. (2018). Opportunities and challenges in Supply Chain Collaboration with Blockchain. IRDITECH 2018 Uluslarararası AR\&GE, İnovasyon ve Teknoloji Yönetimi Kongresi Bildiriler Kitab1, 121-128. İstanbul, Okan Üniversitesi. 18 May1s 2018.

Arena, M., Arnaboldi, M., \& Azzone, G. (2010). The organisational dynamics of Enterprise Risk Management. Accounting, Organisations and Society, 35 (7), 659-675.

Ayers, J.B., (2010). Supply Chain Project Management: A Structured, Collaborative and Measurable Approach. FL: CRC Press, Taylor\&Francis Group.

Baraldi, E.; Proença, J.F.; Proença, T. \& Castro, L.M. (2014). The supplier's side of outsourcing: Taking over activities and blurring organizational boundaries. Industrial Marketing Management, 43 (4), 553-563.

Başkol, M. (2014). Tedarik Zinciri İlişkilerinde Başari Faktörü Olarak Güven Unsuru: Kavramsal Bir Çalişma. Uluslararası Yönetim İktisat ve İşletme Dergisi, 10 (21), 129-146.

Bendoly, E., \& Jacobs, F.R. (2005). Strategic ERP extensions and use. Stanford, California: Stanford University Press.

Bhakoo, V., \& Chan, C. (2011). Collaborative implementation of e-business processes within the health-care supply chain: the monash pharmacy project. Supply Chain Management: An International Journal, 6 (3), 184-193.

Brogden, J. et al. (2017). SAP BusinessObjects Web Intelligence (WebI) 4.2: The Comprehensive Guide. Boston: SAP PRESS.

Buyya, R., Broberg, J., \& Goscinski, A. (2011). Cloud computing: Principles and paradigms. New Jersey, USA: John Wiley \& Sons.

Camarinha-Matos, L.M., \& Afsarmanesh, H. (2008). Classes of Collaborative Networks. Encyclopedia of Networked and Virtual Organizations. (Eds: Putnik, G.D., Cunha, M.M.), 193-198. PA: IGI Global.

Cao, M., \& Zhang, Q. (2011). Supply Chain Collaboration: Impact on Collaborative Advantage and Firm Performance. Journal of Operation Management, 29 (3), 163-180.

Cao, M., Vonderembse, M.A., Zhang, Q., \& Ragu-Nathan, T.S. (2010). Supply chain collaboration: conceptualization and instrument development. International Journal of Production Research, 48 (22), 6613-6635.

Cengiz, E., ve Aksoy, H. (2017). Tedarik zinciri elemanlari arasinda güven ilişkisi, etik kurallar ve bilgi paylaşiminin tedarik zinciri performansi üzerine etkisi. C. Ü. Íktisadi ve İdari Bilimler Dergisi, 18 (2), 1-22.

Chan, Felix T.S. \& Zhang, T. (2011). The impact of Collaborative Transportation Management on supply chain performance: A simulation approach. Expert Systems with Applications, 38 (3), 2319-2329.

Chen, Jie; Sohal, Amrik S.; \& Prajogo, Daniel I. (2013). Supply chain operational risk mitigation: a collaborative approach. International Journal of Production Research, 51 (7), 2186-2199. 
Chopra,S., \& Meindl, P. (2016). Supply Chain Management: Strategy, Planning and Operations. Edinburgh: Pearson.

Cloutier, C, Oktaei, P. \& Lehoux, N. (2020). Collaborative mechanisms for sustainability-oriented supply chain initiatives: state of the art, role assessment and research opportunities. International Journal of Production Research, 58 (19), 5836-5850.

CMMI (2012). Capability Maturity Model Integration. Software Engineering Institute, Carnegie Melon. www.sei.cmu.edu/cmmi, Erişim Tarihi 10 Haziran 2012.

Das, T.K., \& Teng, B., (2001). Trust, Control and Risk in Strategic Alliances: An integrated framework. Organisation Studies, 22 (2), 251-283.

DHL (2018). Blockchain in Logistics. Perspectives on the upcoming impact of blockchain technology and use cases for the logistics industry. https://www.logistics.dhl/content/dam/dhl/global/core/documents/pdf/glo-core-blockchaintrend-report.pdf. Retrieved on February 5, 2019.

Dirks, K., \& Ferrin, D.L. (2001). The role of trust in organizational settings. Organization Science, 12 (4), 426-439.

Duong, L.N.K. \& Chong, J. (2020). Supply chain collaboration in the presence of disruptions: a literature review. International Journal of Production Research, 58 (11), 3488-3507.

Fan, Y. \& Stevenson, M. (2018). Reading on and between the lines: risk identification in collaborative and adversarial buyer-supplier relationships. Supply Chain Management: An International Journal, 23 (4), 351-376.

Fawcett, S.E. et al. (2011). Information Technology as an Enabler of Supply Chain Collaboration: A DynamicCapabilities Perspective. Journal of Supply Chain Management, 47 (1), 38-59.

Gang, L., Yong-Gen, G., \& Zhi-Huan S. (2013). Evolution of cooperation onheterogeneous supply networks. International Journal of Production Research, 51 (13), 3894-3902.

Ghadge, A., Danny, S. \& Kalawsky, R.S. (2013). A systems approach for modeling supply chain risks. Supply Chain Management: An International Journal, 18 (5), 523-538.

Grötsch, V.M., Bloom, C., \& Schleper, M.C. (2013). Antecedents of proactive supply chain risk management: A contingency theory perspective. International Journal of Production Research, 51 (10), 2842-2867.

Gunasekaran, A. \& Ngai, E.W.T. (2004). Information systems in supply chain integration and management. European Journal of Operational Research, 159 (2), 269-295.

Harland, C., Branchley, R. \& Walker, H. (2003). Risk in supply networks. Journal of Purchasing \& Supply Management, 9 (2), 51-62.

Ha, B.-C., Park, Y.-K. \& Cho, S. (2011). Suppliers' affective trust and trust in competency in buyers: Its effect on collaboration and logistics efficiency. International Journal of Operations and Production Management, 31 (1), 5677.

Heütgel, M., \& Kückelhaus, M. (2018). Blockchain in logistics: Perspectives on the oncoming impact of blockchain technology and use cases for the logistics industry. DHL \&Accenture Whitepaper. http://www.manutencionyalmacenaje.com/es/downloads2/glo-core-blockchain-trend-report.pdf. Retrieved on January $10,2019$.

Ho, D.; Arun, K., \& Shiwakoti, N. (2016). Maturity Model for Supply Chain Collaboration: CMMI Approach. IEEE International Conference on Industrial Engineering and Engineering Management (IEEM), 845-849. Bali, Indonesia, Dec. 04-07, 2016.

Hofmann, E., \& Rüsch, M. (2018). Industry 4.0 and the current status as well as future prospects on logistics. Computers in Industry, 89, 23-34.

Jones, G. (2013). Organizational Theory, Design and Change. Edinburgh, UK: Pearson.

Kamble, S.; Gunasekaran, A., \& Himanshu, A. (2019). Understanding the Blockchain technology adoption in supply chains -Indian context. International Journal of Production Research, 57(7), 2009-2033.

Laudon, K.C., \& Laudon, J.P. (2016). Management Information Systems: Managing the digital firm. Edingurh, UK.: Pearson.

Lavastre, O., Gunasekaran, A., \& Spalanzani, A. (2012). Supply chain risk management in French companies. Decision Support Systems, 52 (4), 828-838.

Lia, G.; Gua Y-G., \& Songb Z-H. (2013). Evolution of cooperation on heterogeneous supply networks. International Journal of Production Research, 51 (13), 3894-3902. 
Marr, B. (2018). How Blockchain will transform the supply chain and logistics industry? https://www.forbes.com/sites/bernardmarr/2018/03/23/how-blockchain-will-transform-the-supply-chain-and-logisticsindustry/\#5cf07f685fe. Retrieved on December 20, 2018.

Pateman, H.; Cahoon, S., \& Chen S-L. (2016). The Role and Value of Collaboration in the Logistics Industry: An Empirical Study in Australia. The Asian Journal of Shipping and Logistics, 32 (1), 33-40.

Pomponi, F.; Fratocci, L., Tafuri, S.R., \& Palumbo M. (2013). Horizontal collaboration in logistics: a comprehensive framework. Research in Logistics and Production, 3 (4), 243-254.

Ramanathan, U., \& Gunasekaran, A. (2014). Supply chain collaboration: Impact of success in long-term partnerships. Int. J. Production Economics, 147 (PART B) 252-259.

Robson, M.J., Katsikeas, C.S., \& Bello, D.C. (2008). Drivers and performance outcomes of trust in international strategic alliences: the role of organizational complexity. Organizational Science, 19 (4), 647-665.

Shacklett, M. (2012). Next Generation Cloud computing for supply chains. WordTrade 100, 25 (1), 18-23.

Simchi-Levi, D., \& Kaminsky, P. (2007). Designing and Managing the Supply Chain. London: McGraw-Hill.

Smith, G.E., Watson, K.J., Baker, W.H. \& Pokorsky II, J.A. (2007). A critical balance: collaboration and security in the IT- enabled supply chain. International Journal of Production Research, 45 (11), 2595-2613.

Skandrani, H.; Triki, A., \& Baratli, B. (2011). Trust in supply chains, meanings, determinants and demonstrations: A qualitative study in an emerging market context. Qualitative Market Research: An International Journal, 14 (4), 391 409.

Soosay, C. A.; \& Hyland, P. (2015). A decade of supply chain collaboration and directions for future research. Supply Chain Management: An International Journal, 20 (6), 613-630.

Sundaramurthy, C., \& Lewis, M., (2003). Control and Collaboration: Paradoxes of Governance. The Academy of Management Review, 28 (3), 397-415.

Tarn, J.M.; Yen, D.C., \& Beaumont, M. (2002). Exploring the rationales for ERP and SCM integration. Industrial Management \& Data Systems, 102 (1), 26-34.

Van Echtelt, F.E.A.; Wynstra, F.; Van Wele, A.J., \& Duysters, G. (2008). Managing supplier involvement in new product development: a multiple case study. Journal of Product Innovation Management, 25 (2), 180-201.

Voluntary Inter-industry Standarts (2002). Collaborative Planning, Forecasting, Replenishment Version 2.0.

Wu, I., \& Chiu M.N. (2018). Examining supply chain collaboration with determinants and performance impact: Social capital, justice, and technology use perspectives. International Journal of Information Management, 39, 5-19.

Yazici, H.J. (2012). Buyer perceptions on the buyer-supplier collaborative relationship and performance: a service example. International Journal of Services and Operations Management, 12 (2), 165-187. 


\section{Extended Summary}

\section{Collaborative Paradigm in Logistics and Supply Chain Management}

Collaboration is a concept that is becoming increasingly important in Logistics and Supply Chain Management (SCM) as a critical success factor. This study aimed at answering the following research questions:

-What is the role and importance of collaboration in logistics and supply chain management?

-What is the role of information technologies in collaborative approach?

-What are the effects of collaborative approach in organizational dimension?

-What are the effects of collaborative approach in managerial dimension?

-What is the role and importance of trust component in collaborative approach?

In the comprehensive literature review performed in this study, the keywords of "Logistics and Supply Chain Management", "Collaboration", "Information Technologies" and "Trust" are used. The reference set utilized covers the resources after year 2001, and it mainly includes prestigious journals, books and book chapters.

In extant literature, collaboration appears as a concept which is intimately associated with the ideas of coordination and integration in the literature. The concept is generally defined as an understanding which involves higher level of information sharing, trust and dependancy when compared with the ideas of coordination and integration (Soosay ve Hyland, 2015). The concept goes beyond integration since it involves technology sharing and highly coupled planning and control systems. Thus, it can be described as the highest form of trust-based relations involving long-term dependancies and win-win benefits for supply chain partners.

This study revealed that collaborative understanding experiences a maturity process in time passing through a number of maturity stages (CMMI, 2012; Akyuz, Gursoy ve Celebi, 2014; Dung, Arun ve Nirajan, 2016). Along with this maturity, the number and scope of the processes that can be managed collaboratively across partners increase in time. Starting with collaboration at the core logistics processes, more strategic and longer-term sharing and jointness in processes, resources and competencies develop, and more and more strategic-level partnerships are enabled. In this philosophy, partners evolve into dependant structures which can act together for the benefit of all of them, with minimum opportunistic behavior and maximum strategic compatibility.

After putting forward the collaboration concept, recent developments in information technology (IT) are comprehensively analyzed in the study as the most critical enabler of collaboration under technological dimension. A variety of information technologies such as Enterprise Resources Planning Systems, Service Oriented Architectures, Enterprise Application Integration Platforms, Cloud technology, RF/ID, GIS, Blockchain, Industry 4.0 concept, IoT paradigm are discussed as the state-of-the-art technologies enabling collaboration. It is revealed that all these technologies serve for traceability, visibility, real-time reporting and analytics and smartness in today's supply chain management. They enable joint problem solving and joint action across partners based on real-time information

Then, effects of collaborative paradigm on organizational and managerial dimensions are discussed in two subsequent sections. From organizational perspective, it is revealed that ITbased collaboration resulted in highly integrated, less hierarchical, leaner and more agile organizational structures in which symmetric access to information is enabled. From managerial perspective, it is put forward that collaborative paradigm requires a real change of managerial 
approach as well as the mindsets of managers. The new understanding requires focus on compatibility of goals and strategies, joint process management, joint decision-making mechanisms and joint performance and risk management systems across partners. It is also highlighted that leadership understanding should also change with this transition. Collaborative paradigm requires leaders who are really open to negotiation, open communication, and collaboration. A collaborative culture valuing collaborative teams have to be created and maintained from managerial perspective.

In the study, trust concept in a multi-partner context is highlighted in a separate section as one of the essential facilitators for the creation and maturity of collaborative paradigm. Multidimensional and difficult-to-model character of the trust concept is put forward. Trust is revealed as one of the most fundamental issues in determining the scope, breadth and length of the strategic relationship. It appears as the main factor which elevates the level of collaboration from operational to strategic level. Hence, trust concept is highlighted as one of the most important requirements of long-term, strategic-level collaboration across partners.

This study revealed that multi-partner collaboration is one of the most crucial SCM concepts that evolves in time. It is clearly stated that collaboration requires proper handling of technological as well as organizational and managerial aspects. Recent technological advances become the foundation by enabling real-time information sharing as well as integrated and synchronized business processes. It became evident that handling the managerial and organizational aspects and ensuring the trust development among partners determine the real success of the collaborative, long-term relationships. Availability of a variety of technologies and consultancy makes the technological aspects somewhat accessible to partners. However, managing the organizational and managerial transition to the collaborative paradigm still stands out on the way to long-term successful multi-partner collaboration.

Consequently, the study put forward that dynamic and technology-enabled organizational structures trusting and depending on each other and managed in a collaborative culture became the current paradigm for Logistics and SCM. 
Optimum Journal of Economics and Management Sciences, Vo1. 8, No. 1- https://dergipark.org.tr/optimum Akyüz-Collaborative Paradigm in Logisticsand Supply Chain Management 